\title{
Psychology information literacy standards
}

\author{
Approved by the ACRL Board of Directors, June 2010 \\ by the ACRL Education and Behavioral Sciences Section Psychology Information \\ Literacy Working Group
}

$\mathbf{T}$ he Association of College and Research Libraries' (ACRL) Information Literacy Competency Standards for Higher Education (2000) provides general performance indicators and outcomes to use in undergraduate settings. The Education and Behavioral Sciences Section of ACRL has charged the Psychology Information Literacy Working Group to create standards for undergraduate psychology students. As a result, the following standards, henceforth referred to as the ACRL Psychology Information Literacy Standards, map the ACRL general Information Literacy Competency Standards for Higher Education into the domain of Psychology. The creation of these standards has followed the example of the Information Literacy Standards for Anthropology and Sociology Students (2008) in two important ways: a) the incorporation of the legal and ethical aspects of information literacy, which comprise the fifth standard for the general ACRL documents, into the first four standards and, b) the provision of concrete examples of sources and research situations. The standards will be useful for psychology liaison librarians as a tool to organize information literacy skills instruction and as a foundation for library/faculty collaboration.

The American Psychological Association (APA) lists 54 divisions of psychology ranging from experimental psychology to educational psychology to psychotherapy. While each of these areas has specific needs, they all adhere to the same principles of research ethics. For this reason we have also considered those portions of the APA Guidelines for the
Undergraduate Psychology Major (2007) that are relevant to information literacy. These guidelines express the underpinnings of undergraduate psychology common to all areas.

The ACRL Psychology Information Literacy Standards also build on the guidelines for minimal training for psychology majors first proposed by Merriam, LaBaugh, and Butterfield (1992). In addition, the creation of the ACRL Psychology Information Literacy Standards included examining the research of librarians who provide instruction for psychology and elicited feedback from psychology faculty to help provide specific performance indicators and outcomes. This includes the identification of relevant information resources.

The main purposes of the ACRL Psychology Information Literacy Standards are to:

- Help psychology liaison librarians and psychology faculty design the content of information literacy instruction for students in psychology.

- Make possible an evaluation of the information literacy skills of psychology students by delineating competencies that should be assessed.

- Encourage psychology liaison librarian and psychology faculty collaboration in the teaching of information literacy as a component of research methods in psychology (Thaxton, Faccioli, and Mosby, 2004).

\section{Standard one}

The information literate psychology student determines the nature and extent of the information needed. 


\section{Performance indicators}

1. Defines and articulates the need for information.

\section{Outcomes include:}

a. Identifies and articulates a topic of interest.

b. Determines with psychology faculty whether research, diagnostics, practice guidelines, statistics, or other types of information are needed.

2. Understands basic research methods and scholarly communication patterns in psychology necessary to select relevant resources.

\section{Outcomes include:}

a. Understands the traditional production flow of scholarly communication in psychology from primary to secondary sources.

b. Understands basic research methods in psychology research, including research design, data analysis, and interpretation. Example: Distinguishes between an empirical study and a literature review.

c. Understands the role of peer review in journal articles. Example: Understands the difference between a peer reviewed article and an article selected by an editor. d. Understands the expanding role of the Web in scholarly communication for selecting appropriate Web sources.

e. Understands the principles of privacy, confidentiality, and other ethical issues related to research methodology in psychology. f. Recognizes the difference between scholarly research and popular sources of information.

3. Understands the costs and benefits of acquiring the needed information.

Outcomes include:

a. Understands that scholarly material can be obtained beyond local library holdings. Example: Uses interlibrary loan. b. Defines a realistic overall plan and timeline to acquire and analyze the needed information.

c. Consults with librarians before paying for information, and recognizes that different institutions throughout the world offer different sources for fee-based information.

\section{Standard two}

The information literate psychology student accesses needed information effectively and efficiently.

Performance indicators:

1. Selects the most appropriate sources for accessing the needed information.

Outcomes include:

a. Identifies and selects appropriate sources for locating relevant books.

b. Identifies and selects appropriate article databases. Recognizes the difference

\section{Background}

This project began in 2006 with a review of the library literature and the American Psychological Association codes and guidelines related to teaching psychology in higher education. The group was chaired by Sally Neal and included Lorna Lueck, Tobeylynn Birch, Deborah Schaeffer, Darlene Nichols, and Cynthia Crosser.

In 2008, the second phase began with the formation of the Psychology Information Literacy Standards Taskforce to write the standards document. The group included Cynthia Crosser (chair), Nancy Goebel
(ACRL Information Literacy Standards consultant), Evelyn Day, and Paul Neff.

The document was revised based on feedback from major stakeholders that included members of the Society for the Teaching of Psychology of the American Psychological Association and members of the Education and Behavioral Sciences Section (EBSS) of ACRL.

The EBSS Executive Committee endorsed the revised draft in September 2009. The ACRL Board approved the document in June 2010. 
between discipline-specific databases and aggregate databases when using library resources. Example: Identifies databases with significant content for psychology, such as PsycINFOand MEDLINE.

c. Incorporates relevant Web search engines and government sources into scholarly research. Examples: Uses Google Scholar and PubMed.

d. Knows and complies with local, state/ provincial, and federal laws and institutional rules on access to information resources.

e. Consults additional resources with cross-cultural, international, or interdisciplinary content when appropriate.

2. Constructs and implements effectively designed search strategies.

Outcomes include:

a. Uses appropriate psychological terminology for searching databases, recognizing the different effects of using keywords, synonyms, and controlled vocabulary from the database. Example: Uses online thesaurus in PsycINFO.

b. Creates and uses effective search strategies in relevant databases using advanced search features, such as Boolean operators, truncation, and proximity searches. Example: Uses (adolescen* OR teen) and episodic memory.

c. Retrieves scholarly journals, books, and sources appropriate to the inquiry. Example: Understands how to retrieve online journal articles and how to locate journals in the periodical stacks.

d. Seeks out knowledgeable individuals in the library and academic department as part of the search plan. Example: Makes appointment with the library psychology subject specialist.

e. Assesses results to ascertain if there are information gaps and revises or expands search strategy as necessary.

3. Effectively organizes and credits information sources.

Outcomes include: a. Identifies and systematically records all relevant citation information for future use. Examples: Uses vendor storage space on MyEBSCOhost; Exports to RefWorks bibliographic manager.

b. Produces accurate citations and reference lists using the most current documentation style of the American Psychological Association.

c. Demonstrates respect for intellectual property rights by accurately giving credit to the words and ideas of others.

\section{Standard three}

The information literate psychology student evaluates information and its sources critically and incorporates selected information into her or his knowledge base.

Performance indicators:

1. Summarizes the main ideas to be extracted from the information gathered and synthesizes to construct new ideas.

\section{Outcomes include:}

a. Selects the main ideas from resources and paraphrases or identifies verbatim material to be quoted.

b. Recognizes inter-relationships between research results and psychological theories and combines information to produce new ideas with supporting evidence. Example: Indicates that research supports or contradicts a psychological theory.

c. Recognizes that existing information can be combined with original thought, and/or analysis to produce new information and insights into behavior and mental processing.

2. Combines critical and creative thinking, implementing the scientific approach to solve problems related to behavior and mental processes.

\section{Outcomes include:}

a. Examines and compares information from various sources in order to evaluate reliability, validity, accuracy, authority, timeliness, and point of view or bias. Example: Compares results from a traditional 
literature review and a meta-analysis.

b. Recognizes the strengths and weaknesses of different research methods. Example: Understands the difference between quantitative and qualitative research.

c. Understands the need to weigh the evidence and tolerate ambiguity.

d. Understands what constitutes valid evidence and recognizes prejudice, deception, bias, or manipulation. Example: Understands how to recognize or apply the correct statistical tools for a problem. e. Recognizes, understands, and respects the complexity of socio-cultural and international diversity. Example: Compares the concept of intelligence cross-culturally. e. Understands the political and social issues of censorship and freedom of speech as they relate to psychological research. Example: Understands the political implications of research examining gender, ethnic, or racial differences.

3. Compares new information with prior knowledge to determine its value, contradictions, or other unique characteristics.

\section{Outcomes include:}

a. Demonstrates familiarity with the relevant concepts, theoretical perspectives, empirical findings, and historic trends in psychology.

b. Documents the information-seeking process to explain and evaluate the new information gathered.

c. Evaluates the information collected by comparing it with other sources and current theoretical knowledge; considering such things as the limitations of the research instruments and samples available for study. Example: Student interested in rural mental health care notices that most articles deal with urban mental health care. d. Draws conclusions based upon information gathered and integrates new information with previous information. Seeks expert opinion from instructor or other subject specialist to validate the research results and interpretation of the information. e. Extends information query based on new information when necessary. Example: Student expands search on therapeutic tools to include virtual reality therapy after finding a citation discussing this new area.

f. Outlines future research suggested by new information.

\section{Standard four}

The information literate psychology student, individually or as a member of a group, uses information effectively to accomplish a specific purpose.

Performance indicators:

1. Applies new and prior information to the planning and creation of a particular project, paper, or presentation.

Outcomes include:

a. Organizes the content in a manner that supports the purposes and format of the product. Example: Creates a draft or an outline on new treatments for Asperger Syndrome.

b. Integrates the new and prior information, including quotations and paraphrasing with relevant citations to authors of original ideas and information; includes reference section. Example: Correctly cites sources using APA format.

c. Accurately represents team member contributions in collaborative projects.

2. Communicates the product effectively to others.

\section{Outcomes include:}

a. Chooses a communication medium and format that best supports the purposes of the product or presentation and the intended audience. Example: Prepares a poster on effects of ethics on classroom behavior for a regional conference.

b. Uses appropriate information technology applications in creating the product or presentation. Example: Creates PowerPoint presentation on attention deficit disorder with hyperactivity (ADHD) in adults for class assignment.

c. Demonstrates an understanding of intellectual property, copyright, and fair 
use of copyrighted material and posts permission granted notices as needed.

\section{References}

Association of College and Research Libraries. (2000). In formation literacy standards for higher education. Washington, D.C.: Author. Retrieved from www.ala.org /ala/mgrps/divs/acrl/standards/informationliteracycompetency.cfm.

American Psychological Association. (2007). APA guidelines for the undergraduate psychology major. Washington, D.C.: Author. Retrieved from www.apa.org/ed/psymajor_guideline.pdf.

Anthropology and Sociology Section Instruction and Information Literacy Committee Task Force on IL Standards. (2008). Information literacy standards for anthropology and sociology students. Retrieved from www.ala.org/ala/mgrps/divs/acrl/standards /anthro_soc_standards.cfm.

Merriam, J., LaBaugh, R. T., and Butterfield, N. E. (1992). Library instruction for psychology majors: Minimum training guidelines. Teaching of Psychology, 19(1), 34-36.

Thaxton, L., Faccioli, M. B., and Mosby, A. P. (2004). Leveraging collaboration for information literacy in psychology. Reference Services Review, 32, 185-189.

\section{Other works consulted}

American Psychological Association. (2002). Ethical principles of psychologists and codes of conduct. American Psychologist, 57, 1060-1073. Retrieved from www.apa.org /ethics/code2002.html.

Bieschke, K. J., Fouad, N. A., Collins, F. L., Jr., and Halonen, J. S. (2004). The scientifically minded psychologist: Science as a core competency. Journal of Clinical Psychology. 60, 713-723.

Chamberlain, K. (1986). Teaching the practical research course. Teaching of Psychology, 13, 204-208.

Daugherty, T. K., and Carter, E. W. (1997). Assessment of outcome-focused library instruction in psychology. Journal of Instructional Psychology, 24(1), 29-33.
Faix, A., and Hughes, J. (2006). Suntanning as a risky behavio(u)r: Information literacy for research methods in psychology. In D. Cook \& N. Cooper (Eds.), Teaching information literacy skills to social sciences students and practitioners: A casebook of applications (pp. 218-224). Chicago: ACRL.

Hayes-Bohanan, P., and Spievak, E. (2008). You can lead students to sources, but can you make them think? College \& Undergraduate Libraries, 15, 1-2.

Halonen, J. S., Bosack, T., Clay, S., and McCarthy, M. (2003). A rubric for learning, teaching, and assessing scientific inquiry in psychology. Teaching of Psychology, 30, 196-207.

Lampert, L. (2005). "Getting psyched" about information literacy: Successful faculty-librarian collaboration for educational psychology and counseling. The Reference Librarian, 43(89/90), 5-23.

Larkin, J. E., and Pines, H. A. (2005). Developing information literacy and research skills in introductory psychology: A case study. The Journal of Academic Librarianship, 31(1), 40-45.

McCarthy, M., and Pusateri, T. P. (2006). Teaching students to use electronic databases. In W. Buskist \& S. F. Davis (Eds.), Handbook of the teaching of psychology (pp. 107-111). Malden, MA: Blackwell Publishing.

Paglia, A., and Donahue, A. (2003). Collaboration works: Integrating information competencies into the psychology curricula. Reference Services Review, 31, 320-328.

Schlotzhauer, N. (2006). Psychology. In P. Ragains (Ed.), Information literacy instruction that works: A guide to teaching by discipline and student population. New York: Neal-Schuman.

Sutton, E. D., Feinberg, R. P., and Levine, C. R. (1995). Bibliographic instruction in psychology: A review of the literature. Reference Services Review, 23(3), 13-22.

Thaxton, L. (2002). Information dissemination and library instruction in psychology revisited: "Plus ca change..." Behavioral E Social Sciences Librarian, 21(1), 1-14. n 